DOI: https://doi.org/10.21721/p2p.2018v5n1.p260-275

INOVAÇÃO

\title{
FRONTEIRAS CULTURAIS: METÁFORAS OU REALIDADES?
}

\section{Ricardo Almeida}

“Que es la historia de América toda sino una crónica de lo real maravilloso?”

Alejo Carpentier

\begin{abstract}
Resumo
Neste artigo discute-se sobre a representação cultural das fronteiras e suas possibilidades de integração cultural entre os países. Há uma mudança, nos dias atuais, que desloca a fronteira da periferia para a globalização. Porém, essa nova percepção ainda não é totalmente reconhecida pela sociedade e pelos governos quando se trata de elaboração de políticas de integração cultural. Algumas estratégias foram desenvolvidas, como o Plano de Desenvolvimento da Faixa de Fronteira. Conclui-se que somente a adoção de uma práxis humana articulada com as memórias, na sua relação com os indivíduos e com o planeta, permitirá que as comunidades alcancem uma consciência regional global não submissa.
\end{abstract}

Palavras-chave: Representação cultural. Fronteiras culturais. Integração cultural.

\section{CULTURAL BORDERS: METAPHOR OR REALITY?}

\begin{abstract}
This article discusses the cultural representation of borders and their possibilities of cultural integration among countries. There is a changing, today, that shifts the frontier from the periphery to globalization. However, this new perception is not yet fully recognized by society and governments when it comes to developing policies for cultural integration. Some strategies have been developed, such as the Borderband Development Plan in South America. We concluded that only the adoption of a human praxis articulated with the memories, in their relationship with individuals and with the planet, will allow the communities to reach a non-submissive global regional consciousness.
\end{abstract}

Keywords: Cultural representation. Cultural border. Cultural Integration.

\section{INTRODUÇÃO}

As fronteiras costumam ser vistas como limites e como metáforas, mas elas também podem ser compreendidas como territórios de integração cultural. A partir das fronteiras nacionais, por exemplo, é possível refletir, experimentar e vivenciar as relações entre duas ou mais nacionalidades e entre várias culturas que se misturam e formam "espaços compartilhados", com singularidades e diversidades culturais, caracterizados pela memória e gastronomia comuns, pelo bilinguismo, por literaturas híbridas, por atividades transfronteiriças etc. A cultura popular hegemônica ainda apresenta um perfil "regional-nacionalista" e exerce o papel de demarcação dos Estados-Nação, mas está se modificando em função de essas regiões

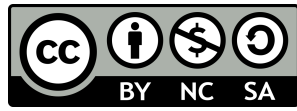


estarem constituindo-se em verdadeiras rotas da integração econômica, política e cultural, com base em novos acordos políticos e comerciais transnacionais.

Sobre esse fenômeno, Eric Hobsbawn (1991) afirma que:

\begin{abstract}
A nação, hoje, visivelmente está em vias de perder uma parte importante de suas velhas funções, nominalmente aquela da constituição de uma 'economia nacional' confinada territorialmente (...). Desde a Segunda Guerra Mundial, mais especificamente desde os anos 60, o papel das "economias mundiais" tem sido corroído ou mesmo colocado em questão pelas principais transformações na divisão internacional do trabalho, cujas unidades básicas são organizações de todos os tamanhos, multinacionais ou transnacionais, e pelo desenvolvimento correspondente dos centros internacionais e redes de transações econômicas que estão, para fins práticos, fora do controle dos governos e Estados (HOBSBAWN, 1991, p.206).
\end{abstract}

A partir dos anos 1980, com o advento da Comunidade Andina, do Mercosul, da chamada Era da Globalização e da internet os processos de integração intensificaram-se nas fronteiras da América do Sul, e foram revelando novas e antigas manifestações de cooperação e de hibridismo cultural. As novas gerações foram ampliando as suas relações históricas e passaram a se conectar com outros países e regiões do planeta, configurando uma nova realidade regional-global bastante complexa e multifacetada. O geógrafo Milton Santos explica que "o espaço se globaliza, mas não é mundial como um todo, senão como metáfora. Todos os lugares são mundiais, mas não há espaço mundial. Quem se globaliza, mesmo, são as pessoas e os lugares" (SANTOS, 1994, p. 13).

Deste modo, as comunidades fronteiriças começaram a abandonar as suas posições históricas de "periferia" para se adequar a uma nova realidade "globalizada". No entanto, essa nova "função" das fronteiras nacionais ainda não foi suficientemente reconhecida pelas pessoas e nem pelos governos quando se trata de elaboração de políticas de integração cultural. Por um lado, porque a cultura hegemônica ainda é influenciada pelos velhos nacionalismos e, por outro, porque as políticas são elaboradas apenas nas capitais e nos grandes centros políticos.

A maioria dos planos de integração entre os países também não envolve as pessoas e os coletivos culturais que vivem e atuam nas áreas de fronteira, e acaba tratando apenas de "nacionalidades", de "cooperação" e de "intercâmbio", e não de "convivência" e de "integração cultural". Um plano de integração cultural precisa servir como um instrumento de reconhecimento da rede de atores e de agentes locais, regionais, estaduais (provinciais), nacionais e internacionais, que atuam nas fronteiras nacionais, pois as experiências são fundamentais, assim como as temáticas, as simbologias e as tecnologias utilizadas. Walter Benjamin destaca a importância da experiência que se contrapõe a noção de vivência. Para ele, enquanto a vivência está saturada apenas de eventos e sensações, a experiência reage aos estímulos por meio da memória e do esquecimento - seus correlatos imprescindíveis 
para a transmissão de saberes simbólicos para as novas gerações (BENJAMIN, 1989, p. $108)$.

\section{UMA CULTURA REAL MARAVILHOSA}

É preciso reconhecer que diversas construções simbólicas vigoram nos países da América do Sul e que muitas delas são modelos mentais herdados dos colonizadores, pois entendem a diversidade cultural apenas como uma soma de territórios, de etnias e de comunidades. No entanto, existem outras bem mais abertas, complexas e singulares, que são frutos da simbiose das diferentes contribuições culturais e que possuem uma cosmovisão da realidade. Ángel Rama diz que é preciso compreender essa transculturação que ocorreu na América Latina ${ }^{1}$ por meio da práxis, e não somente da teoria ou de forma geométrica. Para ele, existem "perdas, seleções, redescobrimentos e incorporações" nessas experiências (RAMA, 1984, p. 47). Deste ponto de vista, as relações se dão de forma concomitante e misturam-se no âmbito de uma reestruturação geral do sistema cultural. O escritor cubano Alejo Carpentier chamou esse fenômeno de real maravilhoso (CARPENTIER, 1993, p. 31).

Por isso, é fundamental a elaboração de um novo discurso no qual as velhas e novas representações reconheçam as origens mais profundas dos seus mitos, símbolos, hábitos e costumes. Nesse sentido, é preciso abandonar o olhar colonial, "de fora", e acrescentar novos contornos à pesquisa científica, assim como à criação artística e cultural. Para intensificar o diálogo com outros movimentos culturais planetários, também será importante compreender que tanto o "nós" como os "outros" constituem um processo cultural caórdico que, segundo este conceito de Dee Hock "não é uma história do passado, embora o passado esteja nela [...], é uma história do futuro, de uma coisa que está tentando acontecer, uma transformação da consciência, da cultura, da sociedade e das instituições como o mundo jamais experimentou" (HOCK, 2006, p. 15).

Esta percepção depende de um olhar "de dentro", prático, histórico e sensível, capaz de juntar as partes com o todo, que mergulhe no passado mais distante sem ficar preso a ele, que represente as culturas urbanas e que faça as suas conexões com as culturas rurais, e/ou das florestas do território em questão, e vice-versa (ALMEIDA, 2015, s/p). Atualmente, esses diálogos estão ocorrendo de forma presencial e também com a utilização de ferramentas da área

\footnotetext{
${ }^{1} \mathrm{O}$ autor cedeu ao senso comum e colonial ao caracterizar a América como sendo somente "latina". Considero que se trata de uma contradição com o conceito de transculturação, pois ele ignora a presença de povos "não latinos", como os indígenas e de matriz africana, por exemplo.
} 
das tecnologias da informação e comunicação. Deste modo, algumas expressões culturais regionais já estão sendo representadas com características complexas e universais, libertandose de concepções maniqueístas e, ao mesmo tempo, extrapolando as visões que estavam presas ao espaço geográfico, à xenofobia, ao etnocentrismo e ao passado.

\section{A DIVERSIDADE, A TRANSCULTURAÇÃO E AS SINGULARIDADES CULTURAIS}

A diversidade cultural e a transculturação que se realizou na América do $\mathrm{Sul}^{2}$ somente serão reconhecidas quando as ciências, juntamente com os mitos e os saberes populares, forem consideradas em suas objetividades e subjetividades. Para isso ocorrer, será necessário, por exemplo, reconhecer que as culturas do Pampa (e da região do Rio da Prata) estão vivas e unem simbolicamente os habitantes de territórios do Brasil, do Uruguai e da Argentina, que a cultura dos povos missioneiros e guaranis mantêm a memória de brasileiros, argentinos, paraguaios e bolivianos, e que os povos das florestas e ribeirinhos unem brasileiros, peruanos, colombianos, venezuelanos e guianenses. Que os rios, as florestas, os parques nacionais e os patrimônios históricos - alguns deles reconhecidos pela UNESCO - são referências simbólicas dessas culturas transfronteiriças.

Há séculos diversas culturas transfronteiriças compartilham símbolos, saberes, hábitos e costumes entre si, como é o caso do mito de Makunaima (pronuncia-se Macunãima) que continua vivo nas comunidades indígenas Pemons, na Gran Sabana, ao norte do continente, da erva-mate (Ilex paraguariensis) que aproxima os moradores do Pampa e das Missões Jesuíticas Guaranis, do calendário natural dos Ashaninkas, que orienta as comunidades que vivem nas florestas do Brasil e do Peru, e dos ritmos de descendências africanas que soam no Platô das Guianas, às margens do rio Oiapoque, bem próximo ao Caribe. Porém, não podemos ignorar que nessas regiões também se instalaram frigoríficos, agroindústrias, mineradoras, hidrelétricas e freeshops, com capital de empresas importadoras/exportadoras transnacionais.

\section{O PAPEL DAS FRONTEIRAS NACIONAIS}

Algumas concepções não conseguem traduzir o interculturalismo (hibridismo cultural) que está explícito nessas regiões do planeta e que já dialoga com o mundo globalizado. Por seu lado, as comunidades transfronteiriças, sem ignorar as diferenças legais dos países, criaram uma

\footnotetext{
${ }^{2}$ Sugiro a utilização de América do Sul ao invés de "latina". Ver nota anterior.
} 
constelação de conceitos e de sentimentos de pertencimento - quase esquizofrênicos - que são mais amplos do que uma cultura nacionalista. Em função destas complexidades experimentadas e/ou vividas, as comunidades das fronteiras da América do Sul podem contribuir para realizar o diálogo necessário entre as mitologias, as ciências e as artes.

As línguas oficiais dos países, por exemplo, não representam um entrave aos sentimentos de pertencimento, pois nelas existe uma floresta de valores simbólicos e mensagens iconográficas comuns que definem e ampliam a abrangência dos territórios de integração cultural. Inclusive, em algumas regiões elas se misturam formando os portunhóis, os guaranhóis y otras mezclas. Se boa parte da academia ainda se debate com a compreensão desses mitos e dos saberes populares, é porque ela está presa aos saberes técnicos aprendidos nos livros e não na práxis (reflexão prática, crítica, histórica e sensível) educadora e libertadora (ALMEIDA, 2015, s/p). Pois é com a sua autonomia, disse Paulo Freire, que penosamente esta consciência vai se construindo, e a liberdade vai preenchendo o 'espaço' antes 'habitado' pela dependência [...] No fundo, o essencial nas relações entre autoridades e liberdades é a reinvenção do ser humano no aprendizado da sua autonomia (FREIRE, 1996, p. 105).

\section{O BRASIL COMO PROBLEMA E COMO SOLUÇÃO ESTRATÉGICA}

O Brasil faz fronteira com a maioria dos países do continente sul-americano e, por isso mesmo, assume um papel estratégico para a integração. No entanto, a legislação brasileira é a única que define uma "faixa de fronteira" com a largura de 150 quilômetros ao longo do limite estatal, considerando-a como uma região distinta e sujeita à legislação específica de controle e segurança. Outros seis países reconhecem faixa ou zona de fronteira de distintas larguras: Chile (que não faz fronteira com o Brasil), Argentina, Bolívia, Colômbia, Paraguai, Peru e Venezuela ${ }^{3}$. As constituições desses países preveem artigos especiais, restringindo a presença de estrangeiros quanto à propriedade de terras, à exploração econômica numa faixa interna que varia de 5 a 50 quilômetros e incentivando a produção das comunidades locais. Enquanto isso, os planos, programas e projetos brasileiros tratam principalmente de infraestrutura e logística, e são limitadores quando se fala em cultura transfronteiriça (ALMEIDA; DORFMAN, 2016, pp. 135-152).

\footnotetext{
${ }^{3}$ Mais informações podem ser encontradas em Benedetti e Bustinza (2017). Estes autores não incluem as Guianas, por falta de informação. Uruguai e o Equador aparentemente se distinguem dos demais países e não têm restrições de ordem securitária, defensiva, de desenvolvimento ou na exploração de recursos nos territórios junto à fronteira.
} 
A maioria dos gestores públicos brasileiros costuma citar apenas o artigo 20 da Constituição do Brasil, que trata da "segurança nacional", mas não menciona o artigo 4", que afirma, no seu parágrafo único, que "a República Federativa do Brasil buscará a integração econômica, política, social e cultural dos povos da América Latina, visando à formação de uma comunidade latino-americana de nações”. Seria preciso também lembrar que a Constituição brasileira, no seu parágrafo $3^{\circ}$ do artigo 215 , destaca os direitos culturais regionais ao afirmar que "o Estado garantirá a todos o pleno exercício dos direitos culturais e acesso às fontes da cultura nacional, e apoiará e incentivará a valorização e a difusão das manifestações culturais". Essa lei estabelece ainda, graças à Emenda Constitucional nº 48, incluída em 2005, que o Plano Nacional de Cultura terá uma duração plurianual, visando ao desenvolvimento cultural do país e à integração das ações do poder público, com a valorização da diversidade étnica e regional.

Por outro lado, a grande mídia brasileira costuma referir-se às fronteiras apenas como um limite do território nacional, e/ou pelo fato de estarem localizadas entre as principais rotas do tráfico e do contrabando. Em alguns casos, são lembradas por ser um destino do turismo de compras, em função das oscilações cambiais e dos freeshops. Até o início dos 1980 as fronteiras eram consideradas pelos governos civis e militares apenas como Áreas de Segurança Nacional e, portanto, em função disso, nesse longo período houve poucos investimentos nessas regiões. Contraditoriamente, em função deste "esquecimento", elas conseguiram manter boa parte do seu patrimônio cultural, salvo raras exceções (ALMEIDA; DORFMAN, 2016, pp. 135-152).

Enquanto essa dimensão da cultura não for assimilada, os beneficiários da exploração de recursos naturais nessas regiões continuam sendo as grandes corporações transnacionais. Uma proposta brasileira feita em agosto de 2000, durante a Reunião de Presidentes da América do Sul, em Brasília, gerou o plano de Integração da Infraestrutura Regional Sul-Americana ${ }^{4}$ e acelerou ainda mais a exploração e a exportação de produtos e matéria-prima do continente. $\mathrm{O}$ velho sonho de integração latino-americana assumiu novas roupagens, e agora está travestido por alianças econômicas e comerciais transnacionais e multinacionais.

\section{OS TRATADOS E OS PLANOS DE INTEGRAÇÃO}

É importante lembrar que o Brasil tornou-se signatário da Convenção da UNESCO sobre a Proteção e Promoção da Diversidade das Expressões Culturais ${ }^{5}$, de 2005; para a

\footnotetext{
${ }^{4}$ Ver

https://pt.wikipedia.org/wiki/Iniciativa_para_a_Integra\%C3\%A7\%C3\%A3o_da_Infraestrutura_Regional_SulAmericana. Acessado em 12/12/2017.

${ }^{5}$ Ver http://unesdoc.unesco.org/images/0015/001502/150224por.pdf. Acessado em 12/12/2017.
} 
Salvaguarda do Patrimônio Imaterial, de 2003; para a Proteção do Patrimônio Mundial, Cultural e Natural, de 1972, e também participou da Conferência intergovernamental sobre políticas culturais para o desenvolvimento, em 1998, e da Convenção de Haya, em 1954.

A partir de 2003, as políticas culturais brasileiras destacaram-se no cenário nacional e internacional por abraçarem antigos e novos desafios. As mudanças que ocorreram na economia nacional e mundial nas últimas décadas foram acompanhadas de novas relações entre o Estado e a sociedade, o que acabou criando as condições para experiências de políticas - econômicas, sociais e culturais - baseadas nas autonomias regionais e no protagonismo global. A cidadania - por meio da democracia direta e de direitos - foi se fortalecendo como um dos pilares do Estado democrático brasileiro, e apoiou-se no dinamismo da sociedade e em suas singularidades regionais. Apesar de o mundo viver um período de tensões e de conflitos de viés nacionalistas, disputas por fontes de energia e/ou étnico-religiosas, o Brasil ocupou um papel central e estratégico nesses processos, e as suas fronteiras pacíficas também representavam janelas de oportunidades de diálogo, de discussão das demandas e de circulação das artes e das culturas no seu sentido mais amplo - nacionais e transnacionais.

A partir de 2005, o governo brasileiro, por meio do Ministério da Integração Nacional do Brasil, adotou uma nova estratégia para a Faixa de Fronteira, que foi avaliada e sofreu ajustes em 2012. A Proposta de Reestruturação do Plano de Desenvolvimento da Faixa de Fronteira $\mathrm{PDFF}^{6}$, afirmava que

O Programa de Desenvolvimento da Faixa de Fronteira (de 2005) caracterizava-se pela presença de projetos desarticulados e fragmentados, movidos por uma lógica assistencialista, sem qualquer planejamento ou orientação programática, resultando na dispersão dos escassos recursos públicos, sem ter impactos na geração de emprego e renda, na organização da sociedade civil e na estruturação das atividades produtivas. Do ponto de vista das relações internacionais, a concepção anterior do Programa colocava toda a ênfase na ideia da fronteira como peça fundamental da defesa nacional e da imposição de barreiras às ameaças externas, implicando, de fato, a imposição de limites nas relações com os países vizinhos.

Esta revisão do plano apresentou uma visão inovadora, pois, até então, a maioria das sistematizações e análises de informações relativas à Faixa de Fronteira considerava apenas o "lado brasileiro" e visava "subsidiar políticas públicas em diversas escalas de ação governamental" e as "tomadas de decisão quanto à aplicação de investimentos, e as ações pela cidadania na região de fronteira". No entanto, apesar desses avanços teóricos, a maioria dos planos, projetos e programas do PDFF, ficou restrita às demandas de infraestrutura (estradas, pontes, hidrelétricas etc.), economia (comércio) e segurança nacional (tráfico e contrabando), ignorando os aspectos da cultura e da arte.

\footnotetext{
${ }^{6}$ Ver http://www.retis.igeo.ufrj.br/wp-content/uploads/2005-livro-PDFF.pdf. Acessado em 12/12/2017.
} 
Este Plano de Desenvolvimento da Faixa de Fronteira afirma que algumas fronteiras enquadram-se no modelo de sinapses (de contato), em virtude do alto fluxo de pessoas e de mercadorias através das linhas limítrofes, apoiadas pelos Estados contíguos, que essas interações também assumem uma função estrutural, pela longa história comum de intercâmbio, cooperação e hibridismo cultural e laboral, e inserem-se na modalidade espontânea ou funcional de integração, em contraposição à modalidade formal (oficial), promovida pelos Estados. Inclusive diz que nelas existe a potencialidade de complementar as carências existentes em ambos os lados da fronteira, por meio de projetos de cooperação interestatais (2001, p. 5).

Considerando esses acúmulos, o desafio passou a ser a redefinição dos conceitos e a elaboração de diretrizes, estratégias, metodologias de reestruturação organizacional, que orientassem as políticas culturais e a construção de uma agenda de ações e eventos que reconhecessem as Culturas Vivas existentes nas regiões de fronteira.

\section{A INTEGRAÇÃO CULTURAL NA FRONTEIRA BRASIL-URUGUAI}

Em 2010, um grupo de militantes culturais articulou uma reunião com o Ministério da Cultura do Brasil - MinC, na fronteira Santana do Livramento (Brasil) e Rivera (Uruguai), na qual também participaram representantes das prefeituras, intendências e alcaldias dos municípios da fronteira Brasil-Uruguai, com o objetivo de compartilhar experiências e organizar ações conjuntas. No dia 30 de julho daquele ano foi entregue a Carta da Fronteira ${ }^{7}$ aos presidentes Luiz Inácio Lula da Silva e José Pepe Mujica.

A carta reconhece que "a histórica convivência entre ambos os povos da fronteira BrasilUruguai produziu um patrimônio cultural com identidade própria" e que "a fronteira constitui um corredor cultural no território do Bioma Pampa, com suas singularidades e diversidade ambiental e cultural". Afirma, ainda, que "a dimensão cultural é um dos eixos integradores para o desenvolvimento sustentável, pois visa a promoção da autoestima e do sentimento de pertencimento, o reconhecimento e valorização do patrimônio histórico e cultural das comunidades fronteiriças" e que "é importante e urgente fortalecer as ações culturais das comunidades da fronteira, bem como ampliar e democratizar o acesso aos serviços e bens materiais e imateriais, às políticas e ações culturais, e fortalecer a economia da cultura, as capacidades e os saberes locais".

\footnotetext{
7 A Carta da Fronteira está anexada ao artigo Fronteiras Culturais / Fronteras Culturales: um processo de autonomias e de convergências. Disponível em http://www.lume.ufrgs.br/handle/10183/170020. Acessado em $\underline{12 / 12 / 2017 .}$
} 
O documento também relacionou alguns objetivos a serem alcançados a curto, médio e longo prazo. Foram realizadas conferências e seminários de cultura de Fronteira, com a adesão das universidades regionais do Brasil e da Universidad de la República - Udelar, do Uruguai, e de representações de várias localidades de fronteira. Cabe destacar entre estes objetivos: 1) a divulgação da Carta de Fronteira, 2) a elaboração de um Protocolo de Cooperação Cultural entre o Brasil e o Uruguai, 3) a criação de uma Cartografia Cultural da fronteira Brasil-Uruguai e do Bioma Pampa, 4) a promoção e articulação dos convênios já existentes, assim como a criação de novos convênios entre as universidades do Brasil e a Universidade de la República, do Uruguai, no sentido de fortalecer o intercâmbio entre pesquisadores, docentes e estudantes e 5) a formação de comissões binacionais de cultura em todas as localidades.

Em outubro de 2010, o Propósito maior do movimento Fronteras Culturales já estava definido e assimilado por todos: era a integração cultural entre o Brasil e o Uruguai, a partir de atividades e eventos nas localidades de fronteira. Com base neste acúmulo de reflexões, em novembro de 2010, o Ministro da Cultura do Brasil, Juca Ferreira, e o Ministro de Educação e Cultura do Uruguai, Ricardo Ehrlich, reuniram-se em Montevidéu e se comprometeram a assinar um Protocolo de Cooperação Cultural. Este Protocolo de Intenções ${ }^{8}$ foi assinado no dia 30 de maio de 2011, pela presidenta Dilma Rousseff, do Brasil, e o presidente José Pepe Mujica, do Uruguai, com o testemunho do Ministério da Cultura da República Federativa do Brasil e do Ministério de Educação e Cultura da República Oriental do Uruguai.

O Protocolo reconhece a importância do protagonismo dos agentes públicos e representantes das organizações sociais e culturais que atuam na fronteira, assim como de todo o processo de mobilização realizado até aquela data. As demandas apresentadas na Carta da Fronteira, firmada pelos prefeitos, intendentes, alcaldes e atores sociais dos municípios da fronteira do Brasil e Uruguai, bem como os resultados da Conferência de Cultura de Fronteira Brasil-Uruguai, realizada nas cidades Jaguarão/Brasil e Río Branco/Uruguai também foram reconhecidos por esse documento.

\footnotetext{
${ }^{8} \mathrm{O}$ documento oficial estava disponível no site do Itamaraty (Brasil), mas atualmente foi possível encontrar apenas uma referência do mesmo na página do Ministério das Relações Exteriores da República Oriental do Uruguai. http://www.mrree.gub.uy/frontend/page?1,inicio,ampliacionactualidad,O,es,0,PAG;CONC;1662;4;D;comunicado-conjunto-de-los-presidentes-de-la-republica-oriental-deluruguay-jose-mujica-y-de-la-republica-federativa-del-brasil-dilma-rousseff;2;PAG;

$\mathrm{O}$ documento completo foi anexado ao artigo Fronteiras Culturais / Fronteras Culturales: um processo de autonomias e de convergências. http://www.lume.ufrgs.br/handle/10183/170020
} 


\section{O CALENDÁRIO DA INTEGRAÇÃO CULTURAL BRASIL-URUGUAI ${ }^{9}$}

Em 2013, passados quase três anos do início do processo de mobilizações, representantes do movimento Fronteras Culturales apresentaram e aprovaram a proposta de criação do I Calendário da Integração Cultural Brasil-Uruguai num grupo de trabalho (Educação e Cultura) e também na reunião do Comitê de Fronteira, realizada na fronteira Aceguá-Acegua. No dia 27 de setembro daquele ano, em Bagé, foram definidos os critérios para a seleção de eventos que fariam parte do primeiro Calendário da Integração Cultural e escolhida uma comissão binacional encarregada de avaliar o grau de integração já alcançado por cada proposta. Os critérios de avaliação foram os seguintes: 1) O evento simboliza a integração entre os dois povos? 2) O evento gera trabalho e renda na região? 3) Coletivos brasileiros e uruguaios participam desde a etapa de organização do mesmo? e 4) Há um reconhecimento público? Na primeira edição foram selecionados 17 eventos, mas o calendário permaneceu aberto para novas adesões, que foram surgindo sem pedir licença.

\section{NOVOS AVANÇOS E CONQUISTAS}

Em junho de 2014, na fronteira Jaguarão-Río Branco, foi realizado o terceiro Seminário de Integração Cultural, com o objetivo de debater o Protocolo de Intenções Culturais Brasil Uruguai, assinado em 2011, e, a partir dele, elaborar planos de ações para os municípios de fronteira. Foram apresentadas propostas nas seguintes áreas temáticas: 1) Patrimônio, Território e Paisagem Cultural, 2) Editais, Convênios, Intercâmbios e Planos de Capacitação, 3) Cidadania Cultural, Ações e Eventos de Fronteira e 4) Organização e divulgação do movimento Fronteras Culturales.

Somando-se a este longo processo de reuniões e de intensas reflexões, a cultura de fronteira também passou a ser reconhecida e debatida nas instâncias de decisão do Mercosul como o Parlamento do Mercosul (Parlasul), o Fundo para a Convergência Estrutural do Mercosur (Focem), a Rede Mercocidades e as Reuniões de Alto Nível. Esta conquista deveuse fundamentalmente à capacidade criativa dos artistas, produtores, mestres e coletivos culturais que, juntamente com as universidades e as administrações públicas locais, conseguiram manter os projetos por meio de políticas públicas e autônomas, alinhadas ou não aos programas e planos culturais dos governos nacional, do Uruguai, e federal, do Brasil.

\footnotetext{
${ }^{9}$ O calendário de 2014 pode ser visto na página Mais informações no artigo Fronteiras Culturais / Fronteras Culturales: um processo de autonomias e de convergências. http://www.lume.ufrgs.br/handle/10183/170020
} 
Em 2015, durante o encontro Diálogo na Fronteira, em Jaguarão-Río Branco, promovido pelo Ministério da Cultura do Brasil, com apoio do Comitê de Fronteira BrasilUruguai, que contou com a participação do ministro Juca Ferrreira, do Brasil, e da ministra Maria Júlia Muñoz, do Uruguai, o ministro anunciou o lançamento de um plano de integração cultural para todas as fronteiras brasileiras. O Ministério da Cultura do Brasil assumiu o desafio de propor pautas culturais positivas para essas regiões. Ainda em 2015 foi publicado o edital No 10/2015 - Projeto 914BRZ4013, da UNESCO, para elaboração de políticas de integração cultural nas fronteiras do Brasil com os demais países da América do Sul.

Após a seleção e a contratação de uma consultoria especializada, o processo de elaboração do plano ocorreu durante o ano de 2016 e foi entregue para a UNESCO e o MinC em dezembro do mesmo ano.

\section{O PLANO DIÁLOGO NA FRONTEIRA}

Foram entregues cinco produtos que contêm os principais tratados assinados pelo Brasil e os países vizinhos - e dialogam com a área da cultura, da memória da América e destacam o potencial de integração cultural de cada ação/atividade/evento existente. O plano também apresenta as pesquisas de campo realizadas em dez regiões de fronteira e uma relação de projetos viáveis, com as respectivas instituições e organizações envolvidas, assim como a sugestão de empresas estatais e privadas que podem servir como fontes de financiamento dos mesmos.

Nesse plano, as fronteiras não são vistas como limites nacionais, intransponíveis, mas sim como possibilidades de integração social, econômica, política, artística e cultural, como se fossem processos vivos e dinâmicos, que se abrem uns para os outros, e que misturam conhecimentos, sonhos, ritmos, falas, sotaques, sabores, arquétipos e costumes, até revelarem uma consciência regional, binacional, continental e até mesmo global-planetária. Sobre essa complexidade Edgar Morin diz que, é preciso ligar e solidarizar conhecimentos separados ou desmembrados capazes de "prolongar-se numa ética de dependência e solidariedade entre os seres humanos. Um pensamento capaz de integrar o local e o específico em sua totalidade, de não permanecer fechado no local e nem no específico", que fosse apto a favorecer o sentido da responsabilidade e da cidadania (MORIN, 2007, p. 27).

Outra característica do plano Diálogo na Fronteira é a adoção do conceito antropológico de cultura, que inclui o conjunto complexo de conhecimentos, artes, crenças, valores, leis, costumes e hábitos, conscientes ou não, que se manifestam nas comunidades. O propósito do 
plano também é simples e claro (de fácil comunicação e assimilação): buscar a integração cultural entre os países a partir das fronteiras nacionais. No entanto, assim como na experiência em andamento na fronteira Brasil-Uruguai, esse propósito vem acompanhado de critérios claros e objetivos a serem alcançados, tais como: 1) a atividade/evento deve simbolizar a integração entre os povos; 2) deve gerar trabalho e renda na região e 3) deve garantir a participação de representação dos países envolvidos desde a etapa de organização dos mesmos.

A partir dos temas centrais das atividades/eventos existentes, os agentes (sujeitos) locais foram revelando seus significados mais profundos e dando-lhes consistências, gerando um processo rizomático em que as metáforas dialogavam com as realidades, e vice-versa. Segundo Deleuze, "um rizoma não começa nem conclui, ele se encontra sempre no meio, entre as coisas, inter-ser, intermezzo. A árvore é filiação, mas o rizoma é aliança, unicamente aliança. A árvore impõe o verbo "ser", mas o rizoma tem como tecido a conjunção "e... e... e..." Há nesta conjunção força suficiente para sacudir e desenraizar o verbo ser" (DELEUZE, GUATTARI, 1995, p. 36). Este tipo de planejamento participativo não se orientou por uma lógica evolutiva e sim por devires. Dentre estes, devires esquecidos, bloqueados, alguns estavam enterrados, dados como mortos.

Neste processo vivo foram surgindo reflexões sobre uma constelação de conceitos relacionados à gestão de projetos e à integração cultural, entre elas: Quais são as simbologias de pertencimento à cada região de fronteira? Como definir cada um dos territórios de integração cultural? Quais foram os processos transculturação, multiculturalismo, interculturalismo que ocorreram/ocorrem nas regiões? Quais são as ações locais com um pensamento global? Quais são as culturas urbanas, rurais e dos povos das florestas? Quais são as tecnologias utilizadas? Qual é a diferença entre políticas de estados e de governos? Como manter uma relação republicana e federativa nos países? São relações de intercâmbio, de cooperação ou de convivência? Deste modo, as pessoas foram libertando-se e liberando as fronteiras que habitavam nelas, pois estavam orientadas por um propósito que unificava antigos sonhos, guiadas por critérios claros.

O festival Binacional de EnoGastronomia e produtos do Pampa ${ }^{10}$, realizado na fronteira Santana do Livramento (Brasil) e Rivera (Uruguai), a partir de 2014, que já está numa fase madura, é um exemplo do que foi dito antes. Trata-se de uma iniciativa proposta por membros do movimento Fronteras Culturales e abraçada pelo GT de Gastronomia do Governo do Estado do Rio Grande do Sul, junto às administrações municipais, hotéis, restaurantes, escolas,

\footnotetext{
10 http://festivalbienogastronomia.blogspot.com.br/2014/06/o-festival.html?spref=fb
} 
universidades da região e do Ministério do Turismo do Uruguai. O evento busca, por meio da memória afetiva, valorizar a produção alimentar e a preservação de saberes, fazeres e sabores culinários da região, valorizando a produção primária, a cozinha dos povos tradicionais e as ações que potencializam a vitivinicultura, a orizicultura, a gastronomia local e o turismo regional.

A programação do festival prevê diversas ações de cooperação, intercâmbio e convivência, com o objetivo de fortalecer a integração política, econômica e cultural entre os dois países. O Parque Internacional, símbolo da união das duas cidades, recebe uma estrutura montada especialmente para um almoço, além de outras atividades de integração. As ações vão desde o circuito de pratos e vinhos do Pampa - nos bares, hotéis e restaurantes - às visitas guiadas às vinícolas, passando por oficinas, palestras e aulas-show com chefes renomados e comercialização de comida tradicional de rua, exposição de produtos regionais e atividades artísticas. $\mathrm{O}$ fato é que, na sua quarta edição, o festival tem contribuído para reestruturar a cadeia produtiva local (produção de alimentos para o consumo em bares, restaurantes e escolas da região), para capacitar as equipes de merendeiras, de garçons e também para agregar valor aos produtos das indústrias familiares.

Além desse festival, são realizados vários eventos de integração cultural nas regiões de fronteira, com destaque para o Festival Internacional de Cinema da Fronteira e o Festival Internacional de Música no Pampa, ambos em Bagé, a série de seminários Jodido Bushinche, sobre os portunhóis, a Mostra Binacional de Teatro - Mucha Merde, o Festival Internacional de Pandorgas, em Santana do Livramento-Rivera, o Jaguararte e a Feira de Literatura e Arte da Fronteira, em Jaguarão-Río Branco, Festival Pachamama - cinema de fronteira, em Río Branco, Festival Internacional de Cinema das Três Margens, em Foz do Iguaçu-Puerto Iguazú-Ciudad del Este, Rede Mercosul de Audiovisual, em Pelotas, Festival del Guizo, em Paso de Los Libres-Uruguaiana, Festival Internacional de Comida Missioneira, em São Borja-Santo Tomé, Festival América do Sul, em Corumbá, Festival de Teatro - Festin-AÇU, em Guajará MirinGuayaramerín, Festival da Confraternização Amazônica, em Letícia-Tabatinga-Santa Rosa, as Semanas da Consciência Negra, os carnavais internacionais em várias localidades, e as jornadas anuais e itinerantes do movimento Fronteras Culturales. Nestes territórios de integração cultural também existem bens patrimoniais, observatórios de pesquisa, institutos de arte, parques turísticos e outras iniciativas com diferentes temáticas, enfoques e metodologias, tais como: nove mostras e festivais de cinema, 13 mostras e festivais de música, oito mostras e festivais de teatro, 12 mostras e festivais de dança, oito feiras e festas literárias, 14 feiras de artesanato, sete festivais de gastronomia e 12 museus. 


\section{OS TERRITÓRIOS DE INTEGRAÇÃO CULTURAL}

Existe um nítido sentimento de pertencimento cultural na região do Pampa, nas Missões Guarani Jesuíticas, na Bacia do Rio Paraná, no Cerrado, no Pantanal, entre os rios Madeira e Mamoré, no Acre (Povos da Floresta), no Alto Solimões, na Grande Savana, na região do rio Oiapoque e em algumas sub-regiões geográficas e culturais (ver figura abaixo).

A elaboração do plano Diálogo na Fronteira foi orientada pela concepção de território de Milton Santos, que diz:

O território não é apenas o resultado da superposição de um conjunto de sistemas naturais e um conjunto de sistemas de coisas criadas pelo homem. O território é o chão e mais a população, isto é, uma identidade, o fato e o sentimento de pertencer àquilo que nos pertence. $\mathrm{O}$ território é a base do trabalho, da residência, das trocas materiais e espirituais e da vida, sobre os quais ele influi (SANTOS, 2017, p. 96).

Ou seja, partindo do princípio de que a América do Sul foi constituída por diversos fluxos migratórios de diferentes continentes e períodos históricos, pelos povos bantos e sudaneses que foram escravizados e trazidos à força em navios, e pelos povos indígenas originários, o processo de elaboração do plano levou em conta este sentimento de pertencimento cultural singular, complexo e diversificado, as lembranças trazidas das regiões de origem e os avanços das fronteiras econômicas,

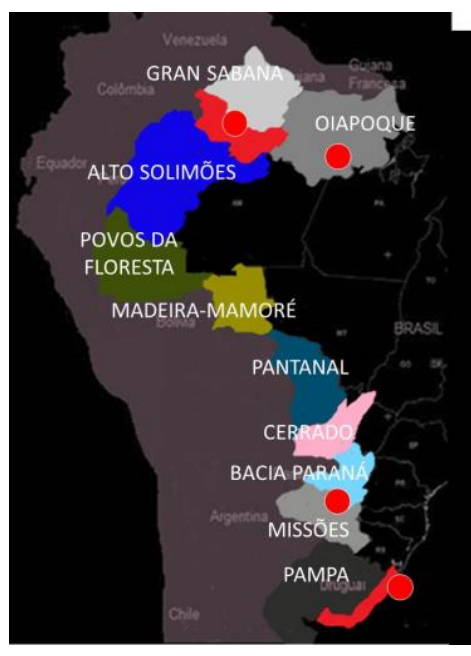
políticas, geográficas e culturais, dos costumes, das crenças, do modo de vida, das técnicas, das artes e das novas tecnologias. Também foram incorporados diversos recortes ambientais e humanos, como as unidades de conservação e as reservas extrativistas, os povos indígenas, os quilombolas, os ribeirinhos, os assentados da reforma agrária e a agricultura familiar, que podem ser considerados como territórios de integração cultural.

A partir da contribuição direta das pessoas entrevistadas, foram identificados dez territórios de integração cultural e algumas sub-regiões (ver figura ao lado), com várias características e atividades comuns, tais como: sete países são membros do Mercosul, dez da Unasul e um da União Europeia. Foram mapeados quatro bens tombados como patrimônio da Unesco, 10 parques nacionais e reservas florestais, 17 universidades Federais e Estaduais e 10 escolas e universidades indígenas. Pelo menos 17 comunidades de povos indígenas, 11 de povos ribeirinhos e nove de povos de matriz africana. 


\section{O FUTURO DO PLANO E OS NOSSOS DESAFIOS}

A elaboração participativa do plano Diálogo na Fronteira desencadeou um processo inédito e dinâmico de reflexões e de planejamento regionalizado, com a formação de uma rede orgânica de colaboradores que se constituíram em embriões de coletivos culturais capazes de perseverar um movimento de integração cultural em cada localidade. As redes, conforme Manuel Castells, "são e serão os componentes fundamentais das organizações. E são capazes de formar-se e expandir-se por todas as avenidas e becos da economia global porque contam com o poder da informação propiciado pelo novo paradigma tecnológico" (CASTELLS, 1999, p. 225).

No entanto, em função da recente ruptura política ocorrida no Brasil, o processo de divulgação do plano preliminar de integração cultural foi interrompido e as comunidades ficaram sem conhecer o plano que ajudaram a elaborar. As diferentes potencialidades deixaram de ser analisadas, assim como as fragilidades e obstáculos que precisam ser superadas em cada região, país por país. Neste sentido, em agosto de 2017 o movimento Fronteras Culturales realizou a sua jornada anual em Santana do Livramento (Brasil) e Rivera (Uruguai) e resolveu incentivar a reflexão sobre os projetos de integração cultural nas fronteiras do Brasil e dos países vizinhos. Para atingir tais objetivos, propôs a criação de um Observatório das fronteiras (junto às universidades regionais), a implementação de uma cartografia das fronteiras e a elaboração de um projeto digital de comunicação à distância e armazenamento de informações (memória dos processos políticos e culturais), além da realização de jornadas culturais no Dia das Américas (12 de outubro) em cada território de integração cultural, seja por meio de seminários e eventos que abordem as temáticas de fronteira.

Tanto as metáforas sobre as fronteiras como o uso das novas tecnologias, junto às atividades de integração cultural existentes nos territórios transfronteiriços, contribuem para a travessia dos limites nacionais e para alcançar uma nova consciência universal. No entanto, enquanto as metáforas são elementos dos discursos, e as tecnologias da informação são meios - mídias - utilizados para auxiliar na comunicação, as experiências e as vivências são relações presenciais que se dão nos territórios de integração cultural. Portanto, somente a adoção de uma práxis humana articulada com as memórias, na sua relação com os indivíduos (sujeitos) e com o planeta, e vice-versa, será capaz de revelar os espelhos enterrados e permitir que essas comunidades caminhem rumo a outro tipo de globalização. Ou seja, que alcancem uma consciência regional-global não submissa. 


\section{REFERENCIAS}

ALMEIDA, Ricardo e DORFMAN, Adriana. Fronteiras Culturais/Fronteras Culturales: um processo de autonomias e de convergências. In: Anuário Unbral das fronteiras brasileiras. Vol. 3. Porto Alegre: Editora Letra1; Instituto de Geociências da UFRGS, 2017.

ALMEIDA, Ricardo. Os outros espelhos enterrados. In: Sul21. [Publicação digital]. 2015. Disponível em <https://www.sul21.com.br/jornal/os-outros-espelhos-enterrados-por-ricardoalmeida>. Acesso em 12/12/2017.

BENJAMIN, Walter. Charles Baudelaire: um lírico no auge do capitalismo. Obras Escolhidas, Vol. III São Paulo: Brasiliense, 1989. .

CARPENTIER, Alejo. Obras Escogidas. Santiago de Chile: Editorial Andres Bello, 1993.

CASTELLS, Manuel. A Sociedade em Rede. A era da informação: economia, sociedade e cultura. Volume 1. $6^{a}$ edição. São Paulo: Paz e Terra, 1999.

DELEUZE, Gilles \& Guattari,Félix. Mil Platôs - Capitalismo e Esquizofrenia. Vol. 1. Rio de Janeiro. Editora 34, 1995.

FREIRE, Paulo. Pedagogia da autonomia. Saberes necessários à prática educativa. São Paulo: Editora Paz e Terra, 1996.

HOBSBAWN, Eric. Nações e nacionalismo desde 1870. São Paulo: Editora Paz e Terra, 1991.

HOCK, Dee. Nascimento da Era Caórdica. $5^{\text {a }}$ edição. São Paulo: Cultrix, 2006.

MORIN, Edgar. Educação e complexidade. Os sete saberes e outros ensaios. São Paulo: Cortez, 2007.

RAMA, Ángel. Transculturación narrativa en América Latina. $1^{\mathrm{a}}$ ed. México: Siglo XXI, 1984.

SANTOS, Milton. Por uma outra globalização - do pensamento único à consciência universal. Rio de Janeiro: Record, 2017.

SANTOS, Milton. Técnica, espaço, tempo: globalização e meio técnico-científico internacional. São Paulo: Hucitec, 1994. 